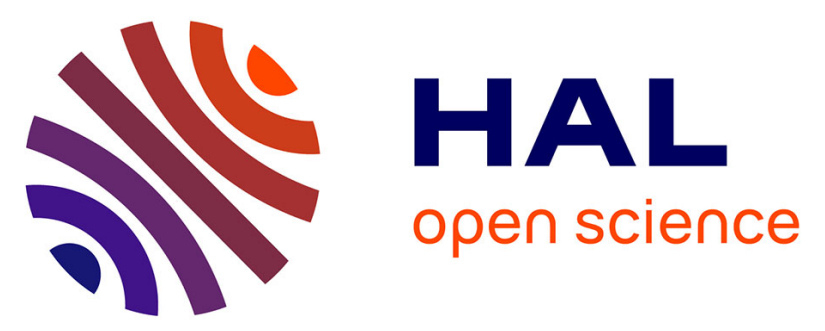

\title{
A transdisciplinary method, knowledge model and management framework for climate change adaptation in mountain areas applied in the Vercors, France \\ Léita Tschanz, Marie-Pierre Arlot, Félix Philippe, Laure Vidaud, Samuel \\ Morin, Eric Maldonado, Emmanuelle George, Thomas Spiegelberger
}

\section{To cite this version:}

Léita Tschanz, Marie-Pierre Arlot, Félix Philippe, Laure Vidaud, Samuel Morin, et al.. A transdisciplinary method, knowledge model and management framework for climate change adaptation in mountain areas applied in the Vercors, France. Regional Environmental Change, 2022, 22 (1), pp.15. 10.1007/s10113-021-01862-3 . hal-03543278

\section{HAL Id: hal-03543278 \\ https://hal.science/hal-03543278}

Submitted on 25 Jan 2022

HAL is a multi-disciplinary open access archive for the deposit and dissemination of scientific research documents, whether they are published or not. The documents may come from teaching and research institutions in France or abroad, or from public or private research centers.
L'archive ouverte pluridisciplinaire HAL, est destinée au dépôt et à la diffusion de documents scientifiques de niveau recherche, publiés ou non, émanant des établissements d'enseignement et de recherche français ou étrangers, des laboratoires publics ou privés. 
A transdisciplinary method, knowledge model and management framework for climate change adaptation in mountain areas applied in the Vercors, France

Léïta Tschanz ${ }^{1,3}$ (Itschanz@gmail.com), Marie-Pierre Arlot $^{1}$ (marie-pierre.arlot@inrae.fr), Félix Philippe $^{1}$ (felix.philippe@inrae.fr), Laure Vidaud ${ }^{1}$ (laure.vidaud@inrae.fr), Samuel Morin ${ }^{2}$ (samuel.morin@meteo.fr), Eric Maldonado¹ (eric.maldonado@inrae.fr), Emmanuelle George ${ }^{1}$ (emmanuelle.george@inrae.fr),Thomas Spiegelberger ${ }^{1,4}$ (thomas.spiegelberger@inrae.fr)

${ }^{1}$ Univ. Grenoble Alpes, INRAE, LESSEM, Grenoble, France

${ }^{2}$ Univ. Grenoble Alpes, Université de Toulouse, Météo-France, CNRS, CNRM, Centre d'Études de la Neige, 38000 Grenoble, France

${ }^{3}$ Aix-Marseille Université, UMR7263, CNRS-IRD, Avignon Université

${ }^{4}$ Univ. Grenoble Alpes, INRAE, LTSER France, Zone Atelier Alpes, 38000 Grenoble, France

Corresponding author

Marie-Pierre Arlot | INRAE Grenoble, 2 Rue de la Papeterie, 38402 Saint-Martin-d'Hères, France | marie-pierre.arlot@inrae.fr | +33476762704

KEYWORDS: climate change adaptation, mountain, social-ecological systems, knowledge management, modelling, climate services

\section{ABSTRACT}

Strategies for adapting to climate change are crucial to sustain human development while ensuring the supply of ecosystem services, especially in mid-altitude mountains. This paper presents main methodological developments and results of an inter- and transdisciplinary research that was applied to the Vercors massif in southeastern France. The approach linked regional climate projections with impacts on social-ecological systems, socio-economic activities, as well as adaptation capacities and management responses. We built on an extensive participatory process and an in-depth analysis of expert and local knowledge. This process provided a generic and transdisciplinary knowledge model together with an integrated framework for adaptation management (AMS-MAIA method). Our analyses showed that many adaptation practices were already underway in the study area, implicitly or explicitly, and highlight key functions and some relevant cross-sectoral insights for adaptation. The research also assisted in collecting information on climate sensitivity through social-ecological indicators across spatial units. It provided resources and a prototype of web-based tools to assist local communities in setting up cross-sectoral adaptation strategies. We offer an original method for governing adaptation based on management standards and continuous improvement, while 
highlighting limitations of such formal and stringent approaches that require social and political license.

\section{INTRODUCTION}

Mountain regions are prone to widespread climate change impacts, with specific adaptation challenges. Beyond a synthesis of existing relevant knowledge, Hock et al. (2019) emphasise the lack of formal evaluations and the numerous barriers that undermine implementation for climate change adaptation. They also highlight the opportunity for improved adaptation processes, which can address both climate change and sustainable development objectives by including citizen science, local knowledge and evidenced-based approaches. Indeed, based on multiple studies around the world, Reyes Garcia et al. (2016) underline the relevance of hybridising different sources of knowledge from citizens, scientists and policy-makers for addressing climate change issues and conducting climate change research. McDowell et al. (2019) confirm the existence of numerous discrete adaptation actions and research projects in glaciated mountain systems, together with the emergence of explicitly mountain-focused adaptation research. However, they point out various shortcomings, such as the lack of consistent and comparable information, and stress the key issues of developing participatory approaches with researchers and practitioners, along with the need to better include the socioecological dimensions of climate change. As reviewed by Webb et al. (2019), a wide array of adaptation support products, knowledge and decision supporting services, involving scientific and local knowledge on adaptation, have been developed over the past decade, most commonly process guidelines and web-based portals, documents, and face-to-face or networked supporting services. However, the authors question the ability of all these adaptation support tools to effectively meet end users' needs and to fit in with specific contexts and decisions. They point out that a key responses to these limitations is the cooperation between tool developers and users, and more generally a long-term relationship between scientists and stakeholders. Lastly, in their mapping of academic research on climate change adaptation of European mountain systems, Vij et al. (2021) detail the achievements and the gaps in mountain adaptation research. They point out that researchers, who mainly focus on biotechnical solutions, are most often limited to a single-issue sector with some important sectors being left out, while crosscutting approaches and adaptation governance questions are insufficiently addressed. 
In this study we addressed these different issues using an inter ${ }^{1}$ and transdisciplinary ${ }^{2}$ research experience consistent with the concepts and experiences proposed by Nicolescu (1996), Gaziulusoy et al. (2016), Hoffmann et al. (2017) and Klein (2020). This experience was launched in response to policy expectations for designing an interdisciplinary, integrated and cross-sectoral approach for adaptation, allowing implementation to the level of small regions with a strong participatory basis. The research was designed with four main scientific and applied objectives: to collect and provide data at a local level; to explore a participatory and transdisciplinary approach in order to associate local, expert and scientific knowledge; to develop a systemic and integrated approach at the scale of a small region in an evidence-based approach; and finally, to give operational elements for adaptation to climate change.

The diversity of the topics to be covered did not allow for the development and operationalisation of in-depth research over the entirety of issues involved. Instead, this paper mostly focuses on the interand transdisciplinary experience, providing methodological proposals, data and tools for understanding and operationalising adaptation, before opening a reflexive discussion on the achievements and the limits of this experience.

\section{GENERAL CONCEPTS AND METHODS}

\subsection{RESEARCH CONTEXT}

The research was conducted within the AdaMont project, carried out from 2015 to 2018, and was continued in the context of more operational transfer programs in 2019 and 2020. This policy-oriented research was specifically designed to respond to a call of the French Ministry of the Environment, in order to support the progress and the operationalisation of the French National Plan for Adaptation to Climate Change ${ }^{3}$, which includes some mountain-specific stakes. This call specifically asked for an interdisciplinary and transdisciplinary approach, together with an integrated and cross-sectoral approach for adaptation that could be implemented in small regions with a strong participatory basis. The project also had the ambition to contribute and to facilitate emerging climate services ${ }^{4}$.

1 Interdisciplinary research: an enrichment through the sharing of knowledge of its own disciplinary field by deepening a particular approach, while preserving a cohesive frame of reference (Nicolescu 1996) and without ignoring the others.

2 Transdisciplinary research: "a comprehensive, multiperspective, problem- and solution-oriented approach that transcends disciplinary boundaries and bridges science and practice" (Hoffman et al. 2017).

3 https://climate-adapt.eea.europa.eu/news-archive/french-national-adaptation-plan-for-climate-changefor-the-period-2018-2022-launced

4 Definition from WMO GFCS (World Meteorological Organization, Global Framework for Climate Services): "Climate services provide climate information to help individuals and organisations make climate smart decisions." (https://gfcs.wmo.int/what-are-climate-services) 
The AdaMont project focused on the Vercors massif, in the central part of the French Prealps, a 1350$\mathrm{km}^{2}$ mid-range altitude area under continental, oceanic and Mediterranean climatic influences, including a variety of topographic and soil conditions and a high animal and plant diversity. For several years, the massif has experienced severe climate change-related impacts that have affected winter tourism, agriculture, pastoralism, forestry and natural resource management (ORCAE 2016; Francois et al. 2019). The Vercors massif hosts a Regional Natural Park, which was a partner of the project. Together with public stakeholders and economic actors, park administrators have been increasingly concerned about climate change mitigation and adaptation solutions, especially with the specific need to update the local planning documents that define strategic and operational actions of the park and its region. The complementary work done in 2019 and 2020 focused on data enrichment with further field data collection, and on consolidation and operationalisation of the deliverables of the project.

\subsection{PARTICIPATORY, INTER- AND TRANSDISCIPLINARY APPROACH}

The participatory approach was developed within the AdaMont project, gathering more than 150 persons in 80 workshops with seven to 30 representatives from major sectors of interest for adaptation: agriculture, forest, tourism, natural risks, water, biodiversity and ecosystem services. The participants were scientists (climatology, social sciences, ecology, risk and information sciences) and engineers (geography and land engineering, quality and research management), experts (Regional Natural Park, technical institutes, local administrations and environmental protection associations), land managers and economic actors (agriculture, forestry, tourism, water management) as well as public authorities (Park administrators, ministries and local administration officers). Three public events involved citizens and students, with 100-300 persons per event.

Workshops intended for participants to exchange knowledge and good practices on climate change impacts and adaptations, and to contribute to an iterative and adaptive process whereby methods and proposals were tested, evaluated and re-designed within a learning process, while benefiting from the facilitation of a researcher in sociology.

Fig. 1 presents a simplified overview of the structure and timeline of the participatory approach that was put in place to support the inter- and transdisciplinary process. It followed a classical sequence as described by Hoffmann et al. (2017). Participants were divided in a six-level organisation, with a steering committee (ST), a technical team (TT), a team of experts (ET), some focus groups (FG), workshops (WS) and public events (PE). Interactions between scientists, experts and actors (land managers, economic actors and public stakeholders) were present at these six levels. The workshops had either thematic or more cross-cutting objectives, while mixing relevant sectors for a crossrepresentation at all workshops. 


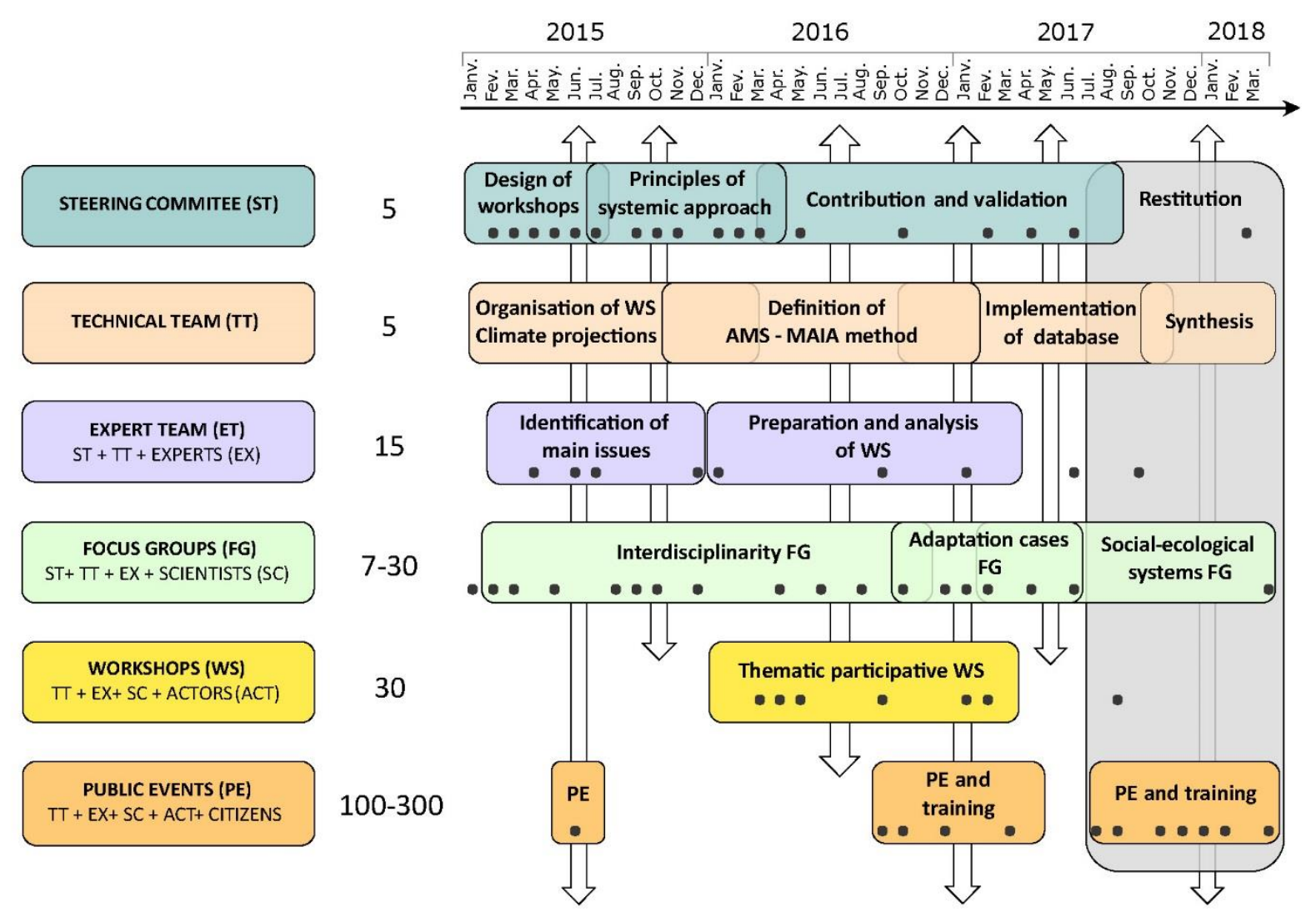

Fig. 1 Working groups structure, project schematic timeline supporting the co-construction, and inter and transdisciplinary approach. The numbers give the range of participants. Grey points represent main meetings and vertical arrows represent exchanges between the six working groups.

\subsection{DOWNSCALING OF CLIMATE PROJECTIONS - the ADAMONT METHOD}

Adaptation at local scale first requires adequate estimates of past and future climate change and their impacts. In mountainous areas, in particular, changes and impacts critically depend on elevation, hence the need to downscale large-scale climate model output. Furthermore, raw output from global (GCM) and regional (RCM) climate models typically exhibits deviations from local observations, and therefore need to be adjusted prior to their use in driving local-scale impact models. Within the AdaMont project, the ADAMONT statistical adjustment method was consolidated and evaluated (Verfaillie et al. 2017). This method used a quantile mapping technique using different adjustment relationships depending on season and weather patterns. It makes it possible to downscale and adjust the daily output of regional climate models, using hourly time resolution observations, in order to provide adjusted hourly time series. This method was implemented for the Vercors massif, and later extended to all mountain regions in France, using the SAFRAN meteorological reanalysis system (Durand et al. 2009) as an observation reference. The ADAMONT method was used to downscale and adjust $13 \mathrm{GCM} / \mathrm{RCM}$ model pairs for Representative Concentration Pathways RCP4.5 and RCP8.5, and four pairs for RCP2.6, from the CMIP5/EUROCORDEX database (Jacob et al. 2014). Verfaillie et al. (2018) provide an example of 
the use of this data set, including atmospheric conditions and also simulated natural snow cover using the Crocus model as an impact model.

\subsection{INTEGRATION OF ADAPTATION KNOWLEDGE AND PRACTICES - THE AMS-MAIA METHOD}

In the absence of comprehensive methods and models sufficient to cover the entire field of the research and in order to develop an integrated and cross-sectoral perspective - a shortcoming that is still pointed out by Vij et al. 2021 - an original process comprising four main steps was proposed and adjusted throughout the research. This process relies on quite classical approaches in themselves, but assembled them into a single operational framework dedicated to climate change adaptation at local and regional level.

1 - Use of DPSIR model and causal chains - The first step of the acquisition and combination of scientific, expert and local knowledge consisted in a logical process closely related to the driverpressure-state-impact-response (DPSIR) conceptual framework (Smeets et al. 1999). Participants of thematic participatory workshops (Fig. 1) were introduced, on the basis of scientists' outputs, to local climate projections as well as to the scientific state-of-the-art and local investigations. They were then invited to comment on observed or anticipated local change hazards and their impacts, on observed or anticipated local changes on the states of ecosystems and socio-economic activities, and finally on existing or potential responses, or adaptation of good practices for addressing these issues.

2 - Design of the knowledge model, using a central concept for the adaptation cases - The design of a knowledge model paved the way towards a better capitalisation and management of the information collected during the workshops. This model described, in a qualitative way, all the components of the regional adaptation system at the scale of the study region (Fig. 2): climatic events and impacts, spatial units, interested parties and functions, adaptation actions and action plans with interested parties and their functions. Spatial and functional units such as administrative regions, management perimeters and social-ecological units were introduced in order to help define the specific areas at stake. 


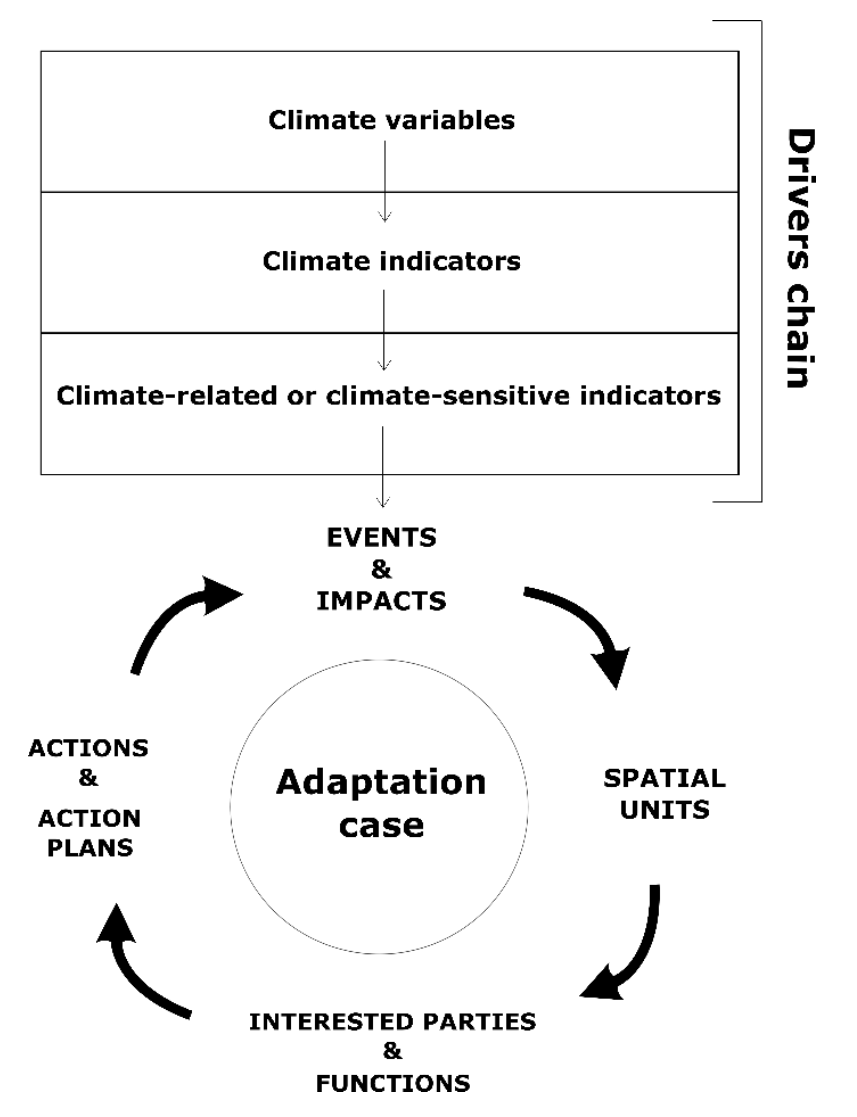

Fig. 2 Diagram of the knowledge model

The international standard Unified Modelling Language $\mathrm{UML}^{5}$, usually used for specifying software systems, provided guidelines to develop the knowledge model, with the support of information scientists in the field of risk decision support (Vidaud-Barral et al. 2020). In analogy with the concept of use case diagram provided by UML to detail a system's functionality, a concept of adaptation case was conceived as a central pivot for the model (Fig. 2).

This concept of adaptation case provided the frame for a structured response to a climate change adaptation issue, using the wording "Adapt what to what". It brings together all the information related to this adaptive response in a "what, who, where, when, how and why" approach, using and connecting the different components of the knowledge model (Fig. 2). A list of different adaptation actions is then proposed for each of these adaptation cases.

3 - Setting up an integrated framework for managing adaptation - An integrated framework was specially set up, together with the concept of adaptation case, with the aim of promoting an accurate, rigorous and generic definition of the different components of the adaptation case. This framework was built using different international concepts and standards in the fields of process and quality

\footnotetext{
${ }^{5}$ https://www.iso.org/standard/32624.html
} 
management, sustainable development as well as business analysis. The first standard used was the ISO 9001:2015 standard for Quality Management System (QMS), and its adaptation for local communities ISO 18091:20197, considering that it was relevant to manage adaptation at the scale of a community or a small region within the framework of such a formalised standard of continuous improvement. Communities or regions facing the challenge of climate change adaptation must in fact implement guidelines, coordinate actions between actors, while ensuring that the needs for adaptation are well characterised and that the responses are satisfactory and allow for gradual adjustments. Each case of adaptation was thus considered as a macro-process within the meaning of ISO9001:2015. This brought together various interested parties around a set of actions oriented towards adaptation, actions that can be classified as proposed in the ISO 9001:2015 standard in steering, implementing or supporting actions. In line with this standard, these processes were particularly informed by a set of indicators which allowed for their continuous evaluation.

The use of the ISO $37101: 2016^{8}$ standard, which established the requirements for a management system for sustainable development within territorial communities, enabled integrating sustainable development requirements together with the management of the adaptation process.

The business analysis model ${ }^{9}$ was used to better define each of the actors' functions, values and stakes, with a particular attention to business stakeholders for the main economic activities of such regions (agriculture, forestry, winter and summer tourism...).

Finally, in line with the ISO Handbook for the Integrated Use for Management System Standards ${ }^{10}$, these complementary approaches were combined to define an integrated management framework for adaptation, called AMS, Adaptation Management System, geared towards non-urban small regions. This AMS management system offered a transcription of the usual components of management systems: field of application, main references used, steering and planning elements, conditions for operational implementation and for evaluation of plans and strategies, including interested parties and their functions ${ }^{11}$.

4 - Indicators and data implementation - In order to further specify the conditions of each adaptation case, some climate variables (e.g. temperature, precipitation, snow depth) and climate indicators were defined to specify the nature of the climatic hazards and their resulting climatic disturbances (e.g. average winter temperature, number of frost days, number of heatwave days). Social-ecological indicators helped to specify the nature of impacts of climate change, covering a wide range of topics

\footnotetext{
${ }^{6}$ https://www.iso.org/standard/62085.html

7 https://www.iso.org/standard/72808.html

8 https://www.iso.org/standard/61885.html

${ }_{9}^{9}$ Business Analysis Body of Knowledge, BABOK 3.0; https://www.iiba.org/standards-and-resources/babok/

${ }^{10}$ https://www.iso.org/publication/PUB100435.html

${ }_{11}$ Sealed envelope $n^{\circ} 23425,2018$, IESF (French registration; https://www.iesf.fr/752 p 50544/pliscachetes.html)
} 
like timber yield, vegetation water balance, end date of growing cycles, or duration of the tourist offseason.

These variables and indicators were defined to respond to the vision and needs of workshop participants, while being scientifically relevant and consistent with the knowledge model and the AMS frame of reference. At this point, they remained qualitative with predefined variation or disturbance modalities (e.g. increase, decrease, temporal variability increase, increase of extreme values). Nevertheless, the design of the model made it possible to introduce quantitative indicators and some characteristic variations and thresholds as they became available.

Adaptation cases, including climate variables and climate and socio-ecological indicators, were filled in a documented sheet on the basis of the material collected during the workshops, and then adjusted with the help of small expert focus groups (Fig. 1, Adaptation cases FG). During the phase of operational transfer of the research, all data was reworked and enriched with data from other participatory experiments, helping to consolidate the whole knowledge model and its indicators, while being implemented in a database and a physical data model. A web platform prototype was created based using a professional knowledge management platform $\left(\mathrm{AIM}^{12}\right)$ along with a user-friendly interface. This platform, called MAIA (Modelling Asset for Improved Adaptation), allowed the entering, exploring and sharing of data and knowledge based on a large collection of adaptation cases and adaptation actions.

\subsection{FOCUS ON THE SOCIAL-ECOLOGICAL APPROACH}

Climate change affects both social and ecological systems and the supply of ecosystem services in mountains areas (Tasser et al. 2017; Locatelli et al. 2017). The concept of social-ecological systems also provided a relevant conceptual framework to address issues of vulnerability, adaptation or resilience to climate change (Thonicke et al 2020).

Accordingly, the AMS-MAIA method was designed to use social-ecological units as a part of the regional system of adaptation (see section 2.3 and Fig. 2). A wide set of social, economic and environmental data for a detailed description of socio-ecological units and their ecosystem services over time is required. Data and indicators about ecosystem services were also integrated within adaptation cases. Nevertheless, very few scientific references were available, at the date of the study, on the effects of climate on social-ecological systems and ecosystem services, or on their adaptation and resilience potential. The work undertaken thus aimed at gaining initial insights into these issues using a three-step focus expert group approach (Fig. 1, Social-ecological systems FG). The overall approach also involved prospective elements (Tschanz 2019).

${ }^{12}$ AIM, Ardans Information Maker (https://www.ardanssoftware.com/solutions/information-maker) 
1 - Definition and mapping of social-ecological units - The approach considered landscape functional units as a first proxy of social-ecological units. The land cover map of the Vercors massif was processed at a $70 \times 70-\mathrm{m}$ grid resolution, using the sliding windows method for two metrics with the Chloe INRAE landscape ecology software (Boussard and Baudry 2017): The Percent Landscape Cover (Pi) for each land cover type as a measure of landscape composition and the Shannon Heterogeneity Index (SHDI), which measures landscape heterogeneity and integrates the notion of fragmentation and connectivity (Burel and Baudry 2000), were computed at three sliding windows $0.5 \times 0.5 \mathrm{~km}, 4 \times 4 \mathrm{~km}$ and $7 \times 7 \mathrm{~km}$. These data were then analysed using Principal Component Analysis and Hierarchical Ascending Classification to obtain a map of functional units of the landscape in the Vercors massif.

2 - Expert assessment of ecosystem services - At the same time, ecosystem services were assessed by a focus group formed with 12 scientists and 15 experts from the Regional Natural Park, technical institutes, local administrations and environmental protection associations in the fields of ecological sciences, forestry, biodiversity and bird conservation. Scientists and experts were individually asked to assess the range and intensity of ecosystem services on the main natural habitats of the massif, using an adaptation of the CICES nomenclature (CICES, 2016) and a methodology based on a capacity matrix (Hermann et al. 2014; Jacob et al. 2015; Campagne et al. 2017). Individual experts' scores were compared and discussed during a workshop. A final weighting provided a common characterisation of ecosystem services assigned to each of the Vercors massif's natural habitats. Ecosystem services bundles were then computed at the scale of the social-ecological units.

3 - Expert assessment of vulnerability and adaptability of social-ecological systems under climate forcing. Data on social-ecological units and ecosystem services were reworked by a focus group of two scientists and five experts from the Vercors Regional Natural Park for three main types of climate forcing based on the 30-year climate projections. The experts sketched projection maps for the impact, vulnerability and adaptability of social-ecological systems undergoing these climate forcings. Ecosystem service bundles were also reassessed in order to estimate the vulnerability of the provision of these services for each social-ecological unit of the Vercors massif. This reassessment referred to the initial land use, without taking into account the impact of climate forcing on the spatial shift of habitats and thus on the spatial extension of social-ecological units.

\section{RESULTS}

\subsection{LOCAL CLIMATE PROJECTIONS: PAST AND FUTURE CHANGES IN CLIMATIC IMPACT DRIVERS}

Fig. 3 summarises the main projected changes across the 21st century, for past (1961-1990 and 19912018) and future periods (2021-2040, 2041-2060 and 2081-2100) for summer precipitation, annual mean temperature and winter snow cover, according to elevation, across the Vercors massif. Consistent with previous studies (Beniston et al. 2018, and references therein), Fig. 3 highlights that changes until the mid-21st century are almost invariant across climate change scenarios. All scenarios 
showed a continuation of the trends from past decades. In contrast, changes for the second half of the $21^{\text {st }}$ century indicated significant differences between a low-emission scenario (RCP2.6) and a highemission scenario (RCP8.5). These examples illustrated the need to combine adaptation to irreversible changes during the coming decades and beyond) and mitigation, e.g. reduction in greenhouse gas emissions, as the only solution to minimise future changes after approximately 2050 (Hock et al. 2019).
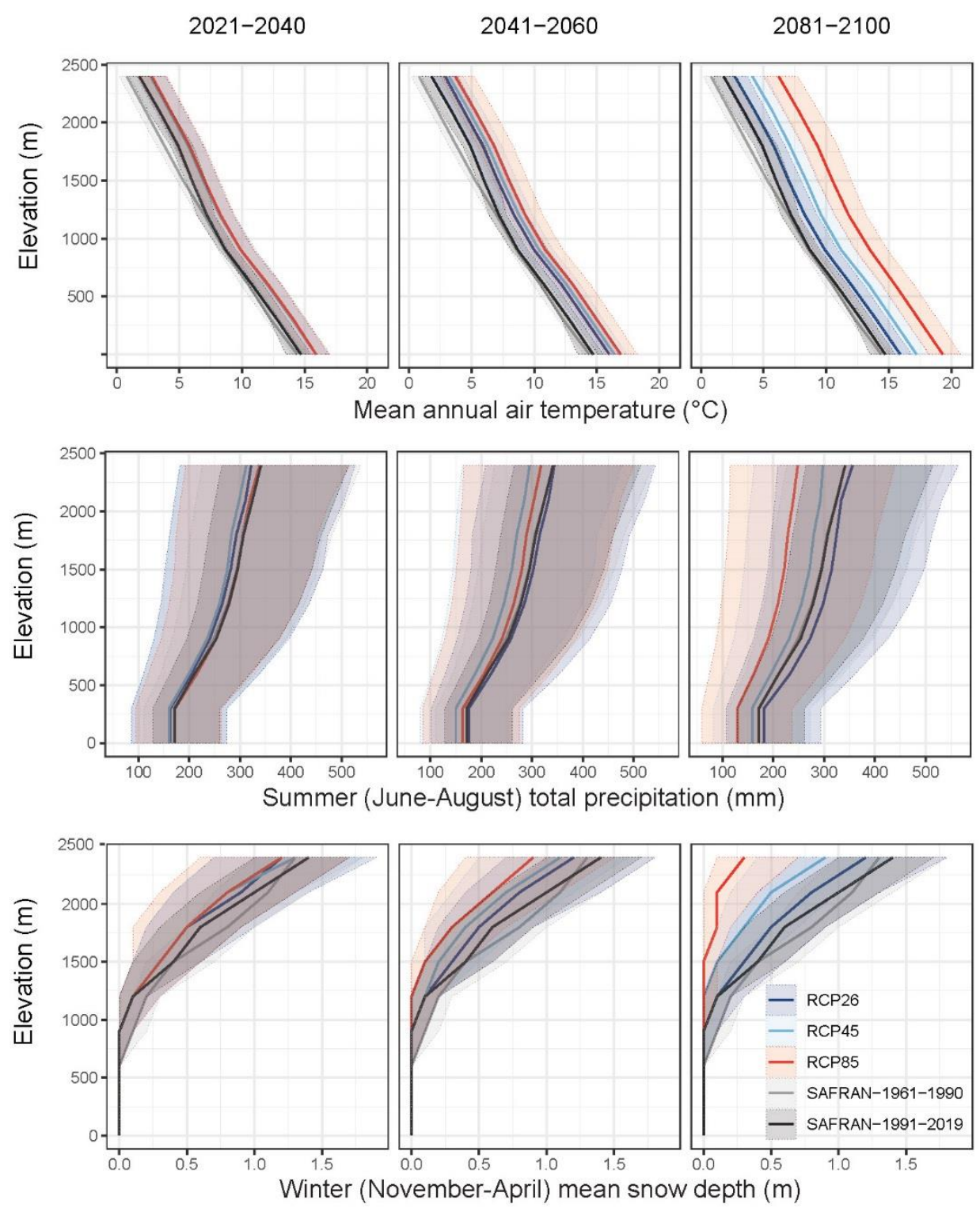

Fig. 3 Summary of the main past and projected values of mean air temperature (top row), summer total precipitation (middle row) and winter mean snow depth (bottom row) in the Vercors massif. Past values shown on each panel correspond to the SAFRAN reanalysis data for the time period 1961-1990 (grey) and 1991-2019 (black). Future projections for RCP2.6 (dark blue), RCP4.5 (light blue) and RCP8.5 (red) are displayed for 2021-2040 (left column), 2041-2060 (middle column) and 2081-2100 (right column). Each panel provides a mean value of SAFRAN reanalysis data and a climate projection for each variable, according to elevations at intervals of 300-m 


\subsection{Climate Change Impacts ASSESSMENT ON SOCIAL-ECOlogical SYSTEMS AND ECOSYSTEM SERVICES}

Six social-ecological units were defined and mapped across the Vercors massif (Fig. 4a) based on the functional landscape units as a first proxy (Cf. section 2.5). The assessment of ecosystem services by the focus group allowed the aggregation of ecosystem service bundles within these six units (Fig. 4b). Assessments show a wide range of services provided for the entire massif. The importance of cultural services accurately reflects the identity of the area, with a high level of tourism activities that rely on both cultural and provisioning services for their role in cultural identity and in shaping landscape.

Degree of impact, vulnerability and adaptation capacity for each of the main habitats were assessed for the three climate forcings. Maps of vulnerability are shown Fig. 4b; detailed maps of impacts and adaptation are provided in Tschanz (2019). The recomputation of ecosystem service bundles at the scale of the entire massif for the same climate forcings showed that severe water shortage affected most ecosystem services. Rising temperatures with constant precipitations showed a more nuanced pattern, with an increase of provisioning services but a critical loss of regulating and recreational services. An increase in extreme events would have a negative impact on all the main habitats and on several provisioning, regulating, recreational and cultural services.

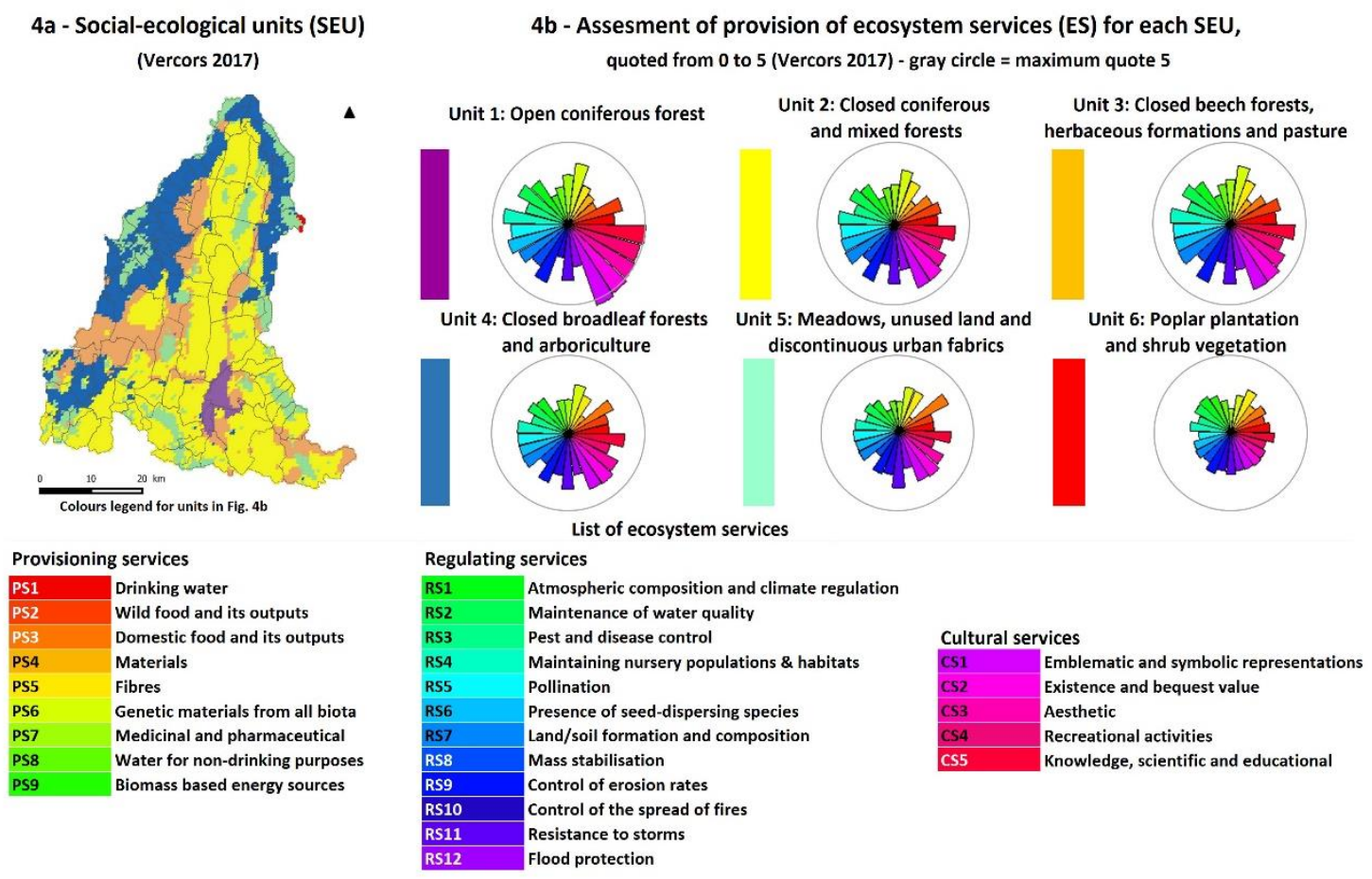

Fig. 4 Assessment of social-ecological units, their ecosystem services and vulnerability in the Vercors massif in 2017 and under three climatic forcings over a 30-year horizon. Social-ecological units are defined with a landscape functional approach 


\subsection{OPERATIONAL ELEMENTS AND CROSS-SECTORAL INSIGHTS FOR ADAPTATION}

Adaptation cases and adaptation actions - For the Vercors massif, the large amount of information and knowledge collected during the workshops was structured in 19 adaptation cases (Fig. 5, left part), referring to sectors of interest based on economic activities or land-use planning-related activities (Fig 5). About 300 adaptation actions were referenced within these 19 adaptation cases. These adaptation actions were either specific to one adaptation case, or shared between some adaptation cases or between sectors. These cross-sectoral adaptation actions represent $25 \%$ of all adaptation actions, with actions dealing with water use governance, forestry and pasture management, and diversification of the tourist offer. Some of these actions were site specific, while others were mountain-specific, and some could be more generic addressing a wide range of contexts.

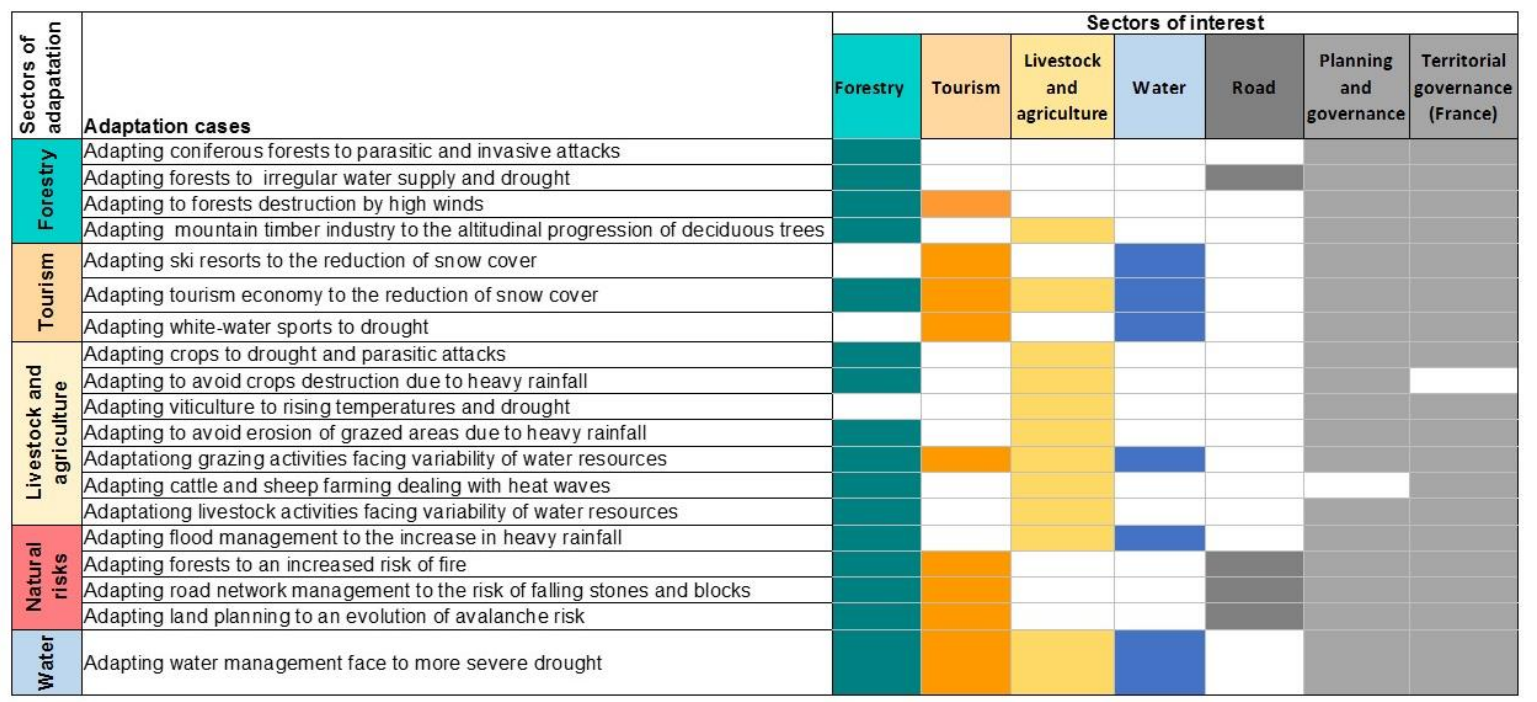

Fig. 5 Adaptation cases and cross-sectoral view of functions involved in the adaptation process (Vercors, 2015-2017). The adaptation cases defined for the Vercors case study are presented in the left-hand column, linked to the main sectors of activity. The functions involved in these adaptations are indicated on the front line, also linked to the main sectors of activity. The coloured boxes indicate when a function is involved in an adaptation case, the colour referring to the sector of activity.

Climate and social-ecological indicators - The information for the 19 adaptation cases allowed us to define more than 200 climate or social-ecological indicators, characterised qualitatively by their variation under the pressure of climate change. These indicators provided a portrait of the sensitivity of the mountain region to climate change through the description of climatic evolutions or hazards, and through the impacts of climate change on social-ecological components.

Among climate indicators, the increase in average temperature remained extensively the primary driver for adaptation needs, followed by the decrease of rain amount and snow. Social-ecological indicators referred to climate change impacts for the main economic or land-use activity sectors of interest. Although many of these indicators concern only one sector, thirty of them are of concern for several sectors as shown Fig. 6, highlighting a cross-sectoral insight of the adaptation process and 
management. Among them, the "biodiversity level" indicator (estimated number of animal and plant species over the massif) is characterised as decreasing and appeared to be the strongest cross-sectoral indicator, linked to five sectors. Eight indicators covering forest extent, plant distribution and water use were characterised as increasing and were linked to the three main sectors of forestry, agriculture and tourism. Some general indicators also referred to increasing conflicts in the use of natural resources.

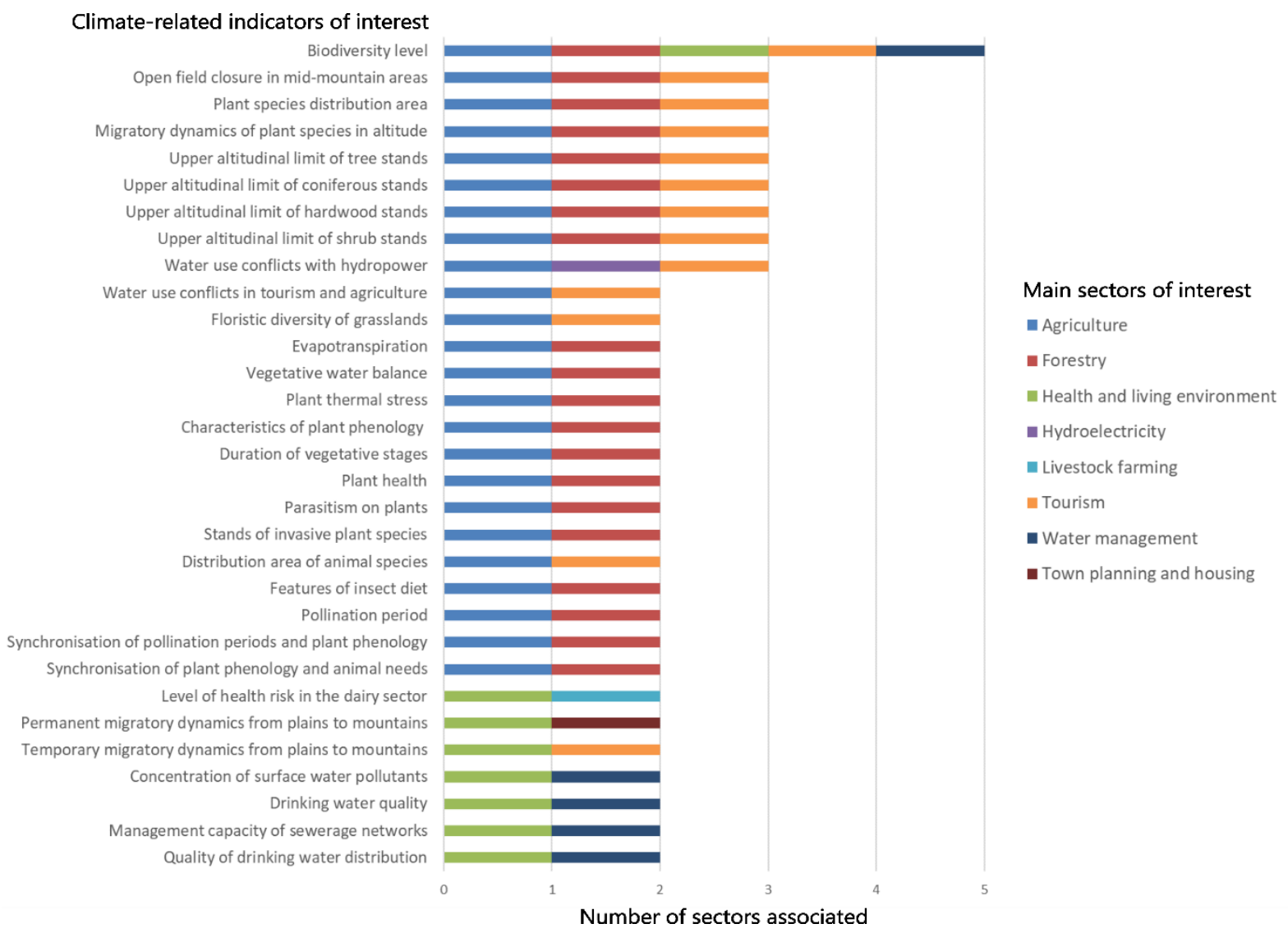

Fig. 6 Cross-sectoral social-ecological indicators identified during field workshops to characterise sensitivity to climate-change (Vercors, 2015-2017). Only the most significant indicators associated with at least two different main sectors are shown out of more than 200 indicators collected during the study. The coloured boxes indicate when an indicator is involved in a sector, the colour referring to this sector.

Interested parties and their function regarding adaptation - More than 50 interested parties who should be involved in the adaptation process were identified for the 19 adaptation cases. Fig. 5 offers an overview of these interested parties, individuals or groups of people that were represented by their main function. Furthermore, it provides a cross-sectoral view of the potential implications of a particular function for several adaptation cases, or for several sectors of interest.

\section{DISCUSSION AND PERSPECTIVES}

Regarding the main scientific and applied issues introduced in Introduction section, four main transversal topics are proposed for discussion and perspectives. 


\subsection{LOCAL DATA AND INDICATORS FOR ADAPTATION}

The research aimed to be as close as possible to the local and regional level, thus requiring a detailed spatial approach. Local state-of-the-art investigations were carried out in this perspective. The knowledge model itself provided various possibilities of spatialisation, while offering flexible boundaries (e.g. administrative, social-ecological, topographical etc.). However, despite the large amount of research and studies carried out in the study region, it remained very difficult to collect enough data with a fairly fine spatial resolution, and the spatialisation of the approach remained rather poor.

The downscaling of climate projections enabled scale-appropriate assessments of climate changes as recommended by McDowell et al (2019). It contributed to defining the issues to be discussed during participatory meetings, but only in a general and qualitative way because of the absence of relevant impact models able to use these projections to inform the various and complex issues of adaptation, a general gap that is even pointed today by Vij et al (2021).

Consistent with conclusions of Ruckelhaus et al. (2105), the definition of a comprehensive set of qualitative social-ecological indicators within the frame of the adaptation cases provided an alternative to the lack of quantitative data. It enabled describing many various aspects of various adaptation issues as well as getting a better understanding of the local manifestations of climate change. These indicators can thus be used as possible criteria for evaluating the impact of adaptation actions, and to monitor them in a real time and continuous improvement approach. They are also useful as triggering criteria for adaptation, and can help identifying some research priorities to support adaptation, especially since they are cross-sectoral or conflicting indicators. The present set of indicators nevertheless still shows some significant gaps due to important thematic issues that have received little or no attention, like energy and health, gaps that are consistent with the ones identified by Vij et al (2021). However, the continuation and extension of the participatory work can make it possible to progress quickly on these themes.

Social-ecological approaches can give interesting complements in the iterative evidence-based science-policy process (Ruckelshaus et al. 2015), providing a rich panel of value metrics such as bundles of ecosystem services, vulnerability and capacity of ecosystem adaptation. The exploratory and participatory social-ecological approach used during this research thus enabled downscaling the scientific and expert information available at a local and regional level, and led to a first evaluation of trajectories of ecosystem services bundles' under different climate scenarios. This expert and participatory approach has the potential to be applied to less information-rich regions. Furthermore, the field tests confirmed the strong interest and expectations of land managers towards the assessment of ecosystem services to provide relevant information for land planning and management issues, in line with the analysis by Vannier et al. (2019). 
The social-ecological approach tested in this research must be completed with a better integration of the socio-economic components, by taking into account changes in the spatial distribution of vegetation, and by integrating the most recent work on resilience and adaptative capacity of ecosystems (Thonicke et al 2020) into these issues of day-to-day adaptation.

\subsection{PARTICIPATORY PROCESS AND KNOWLEDGE MANAGEMENT}

Participatory approaches are increasingly advocated to produce usable climate adaptation processes by mixing scientific, expert and local knowledge and know-how, but raise important questions starting with the one of the representativeness of the participants (Cvitanovic, 2019). They remain cumbersome and costly to implement, and need the support of facilitators and engineering capacities (Gaziulusoy et al. 2016). They can also suffer from the limitation of methodologies, tools and knowledge that are rarely shared and often poorly optimised (Meadow et al. 2015; Webb et al. 2019). Most often, they require the establishment of a knowledge base, the building and testing of theories on adaptation that allows revealing patterns and insights that may be lost if not analysed systematically (Vij et al. 2021).

Leading a large participatory approach was one of the main objective of the research. The material collected during the participatory workshops was important but disparate despite the use of a common DPSIR template. The topic of knowledge management quickly became one of the major challenges of this research. A knowledge model was specially built in the absence of a suitable model able to describe the complexity of the regional system to be studied together with the little data available.

The material collected was rich, once the information was reprocessed with the knowledge model. However, the model and its central concept of adaptation case remained difficult for actors to appropriate because of its relative exhaustiveness and complexity. We therefore developed a quite simple serious game, which has proved to be a great help towards the appropriation of concepts and the production of data; this encourages continuing research on synergies between participatory knowledge management and gamification approaches (Vidaud-Barral et al 2020; Fernandez Galeote et al 2021).

The use of such qualitative participatory model however warrants some caution, as the model currently has few functionalities to ensure its true robustness. However, in contrast with more complex quantitative models, this type of qualitative modelling retains the advantage of being quite quick and easy to implement, and likely to be improved gradually with new expert knowledge and participatory experiences. In addition, the UML design of the model enables interfacing with other models that can shed light on certain issues, like simulation models, multi-agent or Bayesian network models (Berthier, 2007; Fusco, 2004). 
The participatory approach furthermore required a substantial commitment and considerable effort and permanent adaptation, confirming the need for a support from facilitators and engineering capacities. Despite these important efforts, the success in terms of participant representability was correct but moderate; the mobilisation of elected officials and citizens remained for example rather difficult beyond one-off events.

This participatory experience therefore encountered the difficulties classically described for participatory approaches (Reed, 2008; Cvitanovic, 2019) and have only partially resolved them despite the technical support of the knowledge model and the significant human and financial resources. It therefore seems necessary to deepen and continue to equip research on participatory processes in support of policies and adaptation strategies at a regional level (Cvitanovic, 2019).

\subsection{INTER- AND TRANSDISCIPLINARY APPROACH}

The research meets the main characteristics of transdisciplinary projects reviewed in section 1.2: integrated in a concrete case study and contributing to raising awareness of the complexity of the questions asked, leading to a functional innovation and requiring a long-term approach with partners. The AMS-MAIA method has helped the inter- and transdisciplinary process, providing a ready-to-use vocabulary common between scientific disciplines, and between scientists and field actors. This approach also brought together a wide range of data (climatic, social, ecological; scientific, local and expert) in a single integrated operational approach that has helped informing a regional adaptation model, all in line with the recommendations of Ruckelhaus et al (2015).

But paradoxically, the choice of using information and management sciences for the necessary work of integration distanced most of the researchers from the project, leading them to consider it as an engineering tool because of the distance with their scientific discipline and its own vocabulary and the lack of time or interest in appropriation of such concepts.

The experience has been considered by local and national stakeholders as a significant milestone in initiating and supporting a participatory and crosscutting approach to climate change adaptation within a small region. A long tradition of collaboration with the Vercors park has provided the longterm continuity necessary for this type of transdisciplinary project (Deffontaines et al. 1982; Brand et al 2013; Otero et al 2018). The project's achievements have been taken up in the new strategic and planning document of the Vercors Regional Natural Park. The knowledge model and its reference system generated in this trans- and interdisciplinary approach can be transferred to other local or regional area and to other issues of environmental transitions.

\subsection{Proposals for adAPtATION MANAgEMENT}

Beyond the knowledge-based model helping to capitalise and share information on adaptation to climate change, this experiment brings some proposals that can contribute to designing new governance practices as proposed by $\mathrm{Vij}$ et al (2021). This issue is essential but particularly complex 
because of the multiplicity of issues to be addressed, the high number of private or public parties of interest and the complexity of their interactions - like the 300 adaptation actions and 50 functions that were characterised during the Vercors' experience.

The concept of adaptation cases provides a first contribution to governance issues. It can provide actors with keys to formalise their adaptation needs and to respond to them in an operational and effective manner within the framework of relevant, traceable and precisely documented strategies. The knowledge model also provides insights into cross-sectoral impacts and actions, helping to identify key functions and some priorities for adaptation.

The research developments also offered a contribution to governance issues that were consistent with the foundations and requirements of the learning organisations (Senge 2015), while providing a first extension towards territorial learning organisations (Cosson 2018) consistent with Gwiazdzinski and Cholat (2021). The introduction of an adaptation management system (AMS), derived from quality management systems (QMS), enables supporting this learning process with a continuous improvement posture, thus meeting the need outlined by Webb et al. (2019) of cooperative and long-term improvement approaches required for climate change adaptation. The AMS reference framework is ready to be used, and can be linked with other reference frameworks, in particular those for sustainable development, responding to the need highlighted by Hock et al. (2019) of defining adaptation patterns that can address both climate change and sustainable development objectives. The AMS is moreover consistent with the ISO 14090 standards published in 2019 (ISO 14090:2019 ${ }^{13}$ ), which specify principles, requirements and guidelines for climate change adaptation.

Lastly, the generic features of the knowledge model (DPSIR, UML) and the international standards used for the AMS-MAIA method (ISO standards, business analysis) offers a good transferability potential for different land types and for various transition issues, while making it possible to easily compare adaptation cases and actions over different regions.

The use of business analysis templates for climate change adaptation issues is now growing in climate change consultants' work; the use of management processes and systems for climate change research modelling or operational issues seemed in contrast more innovative, and this particularly at the launch of the research. The recent definition of the ISO 14090 management standards for adaptation to climate change may contribute to the spread of this type of approach.

Despite the large co-construction efforts made around the approach, technical choices had to be made at times, and the various actors involved in the research have only partially adhered to the choice of using the rather formal framework of quality, continuous improvement and management standards, considered to be too procedural, complex and cumbersome. This difficulty posed by the necessary

\footnotetext{
${ }^{13}$ https://www.iso.org/standard/68507.html
} 
complexity of such integrated approaches and their tools can be overcome by transferring the use of such tools to engineering facilitators who can propose a set of tools and services as part of a climate service.

The regional climate projections generated using the ADAMONT method are now widely disseminated in France by the DRIAS climate services platform ${ }^{14}$ and have also been used the European scale (Morin et al. 2018). Furthermore, they are gradually being implemented to model climate change impacts on natural resources in mountain-related economic activities, like operating conditions for ski tourism in the French Alps (Spandre et al. 2019).

The AMS-MAIA method is included in the prototype of a web platform intended to be used by public or private structures in charge of assisting local and regional stakeholders in setting up adaptation actions and management plans. However considering climate services at the scale of a region remains a challenge (Morin and Arlot 2019). Beyond the scientific and technical challenge, one of the main challenges remains in finding the right organisational and economic model for supporting this type of service, and more broadly a necessary adaptation of governance practices for transitions and adaptation to climate change, to enable and support this type of participatory and cross-cutting approach.

\section{CONCLUSION}

This policy-oriented research had the ambition to mobilise local and expert knowledge to build a crosssectoral and integrated approach to climate change at the scale of a small region. To do this, it combined a large participatory process within an interdisciplinary and transdisciplinary approach in the context of a regional natural park.

The approach was supported by the downscaling of climate projections, and equipped with a knowledge model built on a methodological framework inspired by international standards. A broad local knowledge based on climate change impacts and adaptation actions was produced together with a set of indicators to document these impacts and actions. In that sense, the AMS-MAIA method constitutes a step towards more evidence-based and formal approaches for climate change adaptation.

The research also explored the application of landscape analysis tools and expert focus groups to assess the vulnerability of social-ecological systems to climate change, and to draw the possible impacts on bundles of ecosystem services at a local and regional scale. This aspect remains to be further developed by integrating the most recent work on resilience and adaptive capacity of ecosystems.

\footnotetext{
${ }^{14}$ DRIAS, futures of climat accompanied by a set of indicators (http://www.drias-climat.fr/)
} 
The participatory and qualitative methodology that was developed is generic enough to be applied to different contexts and environmental transition issues, while taking care to integrate scientific knowledge as much as possible, for greater reliability. In particular, it can complement or come upstream of more quantitative sectoral approaches.

This research contributes to the issue of adaptation governance. It provides a framework that is both rigorous but adaptable, which can support ad hoc reflections to define an adaptation plan. It also proposes to implement adaptation plans in a learning and continuous improvement perspective.

The main challenges remain economic, political and cultural in nature. Such approaches may be experienced as complex to appropriate. They need to find mixed public and private economic models to support them and ask for long-term and crosscutting practices.

\section{ACKNOWLEDGMENTS}

This project was funded by the French Ministry of the Environment and has benefited from the key support of the political and technical staff of the French Prealps Regional Natural Parks. The project also benefited from the extensive mobilisation of the researchers and engineers of the INRAE Grenoble research centre. We thank CNRM colleagues involved in this work, in particular Raphaëlle Samacoïts for producing Fig. 3. Many colleagues from research support teams also offered their assistance for this research, and we would like to thank all of them, while extending a special thanks to Emmanuel Jonas, who made a major contribution in the field of business analysis and quality management and to Arnaud Cosson for his valuable insight as a sociologist of organisations. We would also like to acknowledge the team of contractual engineers in charge of the operational course of the project for their investment and significant participation, with particular recognition of Delphine Piazza-Morel. The work of maturation and transfer of the research results was supported by the Technology Transfer Acceleration Company SATT Linksium in Grenoble and INRAE. LESSEM and CNRM/CEN are part of LabEX OSUG@2020. This study contributes to the Trajectories Cross-Disciplinary Project (CDP) Trajectories funded by the French Agence Nationale pour la Recherche within the framework of the IDEX project of Grenoble-Alpes University.

\section{REFERENCES}

Beniston M, Farinotti D, Stoffel M, Andreassen L M, Coppola E et al. (2018) The European mountain cryosphere: a review of its current state, trends, and future challenges, The Cryosphere, 12, 759-794, https://doi.org/10.5194/tc-12-759-2018 Berthier D (2007) An Ontology for Modelling Flexible Business Processes. In: Elleithy K. (eds) Advances and Innovations in Systems, Computing Sciences and Software Engineering. Springer, 
Dordrecht, https://doi.org/10.1007/978-1-4020-6264-3 16

Boussard H, Baudry (2017) Chloe4.0: a software for landscape pattern analysis.

\section{https://www6.rennes.inrae.fr/bagap eng/PRODUCTIONS/Softwares}

Brand F, Seidl R, Le Q, Brandle J, Scholz R (2013) Constructing consistent multiscale scenarios by transdisciplinary processes: The case of mountain regions facing global change. Ecology and Society 18(2):43. https://doi.org/10.5751/ES-04972-180243

Burel F, Baudry J (2000) Ecologie du paysage. Concepts, méthodes et applications, 2e éd., Tec \& Doc, Paris, 355 p.

Campagne CS, Roche P, Gosselin F, Tschanz L, Tatoni T (2017) Expert-based ecosystem services capacity matrices: Dealing with scoring variability. Ecological Indicators 79:63-72.

https://doi.org/10.1016/i.ecolind.2017.03.043

CICES (2016) Towards a common classification of ecosystem services. European Environment Agency (EEA). Revised Final Report v43. http://cices.eu/

Cosson A (2018) De l'organisation au territoire apprenant (From organisation to learning territory)", Working paper.

Cvitanovic C, Howden M, Colvin R.M., Norström A., Meadow A.M. et al. (2019) Maximising the benefits of participatory climate adaptation research by understanding and managing the associated challenges and risks, Environmental Science \& Policy, Volume 94, 2019, Pages 20-31, ISSN 1462-9011. https://doi.org/10.1016/j.envsci.2018.12.028

Deffontaines J-P, Raichon C, De Verneuil B. 1982. Chronique d'une recherche: Réflexions sur l'étude interdisciplinaire d'un système agraire de la Montagne corse. Agronomie 2(3):257-266.

Durand Y, Laternser M, Giraud G, Etchevers P, Lesaffre B et al. (2009) Reanalysis of 44 Yr of Climate in the French Alps (1958-2002): Methodology, Model Validation, Climatology, and Trends for Air Temperature and Precipitation. J. Appl. Meteor. Climatol., 48, 429-449.

\section{https://doi.org/10.1175/2008JAMC1808.1.}

Fernández Galeote D, Rajanen M, Rajanen D, Legaki N-Z, Langley DJ et al (2021) Gamification for climate change engagement: review of corpus and future agenda, Environ. Res. Lett. 16063004 Fusco G (2004) Looking for Sustainable Urban Mobility through Bayesian Networks. cybergeo. https://doi.org/10.4000/cybergeo.2777

Gaziulusoy A.I., Ryan C., McGrail S., Chandler P., Twomey P (2016) Identifying and addressing challenges faced by transdisciplinary research teams in climate change research, Journal of Cleaner Production, Volume 123, 2016, Pages 55-64, ISSN 0959-6526.

\section{https://doi.org/10.1016/i.jclepro.2015.08.049}

Gwiazdzinski L., Cholat F (2021) Territoires apprenants et fabrique de situations. Pistes et enjeux pour la formation et la cité. Luc Gwiazdzinski; Florent Cholat. Territoires apprenants. Un processus 
d'apprentissage émergent à l'approche du réel, Elya Editions, pp.39-61, 2021, 979-10-91336161 〈halshs-03119481)

Hermann A, Kuttner M, Hainz-Renetzeder C, Konkoly-Gyuró E, Tirászi A et al. (2014) Assessment framework for landscape services in European cultural landscapes: An Austrian Hungarian case study. Ecological Indicators 37:229-240. https://doi.org/10.1016/i.ecolind.2013.01.019 Hiwasaki L, Luna E, Syamsidik, Shaw R (2014) Process for integrating local and indigenous knowledge with science for hydro-meteorological disaster risk reduction and climate change adaptation in coastal and small island communities. International Journal of Disaster Risk Reduction 10:15-27.https://doi.org/10.1016/j.ijdrr.2014.07.007

Hoffmann S, Pohl C, Hering JG (2017) Methods and procedures of transdisciplinary knowledge integration: empirical insights from four thematic synthesis processes. Ecology and Society 22(1):27. https://doi.org/10.5751/ES-08955-220127

Hock R, Rasul G, Adler C, Cáceres B, Gruber S et al. (2019) High Mountain Areas. In: IPCC Special Report on the Ocean and Cryosphere in a Changing Climate [H.-O. Pörtner, D.C. Roberts, V. Masson-Delmotte, P. Zhai, M. Tignor, E. Poloczanska K. Mintenbeck, A. Alegría, M. Nicolai, A. Okem, J. Petzold, B. Rama, N.M. Weyer (eds.)]. https://www.ipcc.ch/site/assets/uploads/sites/3/2019/11/06 SROCC Ch02 FINAL.pdf Francois H, Gayrard JL, George E, Labonne S, Nettier B, Philippe F, Piazza-Morel D, Didier Richard D, Veron $F$, (2019) Enjeux et bonnes pratiques d'adaptation pour le territoire du Vercors. Revue Sciences Eaux \& Territoires nº 28-62. DOI : 10.14758/SET-REVUE.2019.2.13 IPCC (2014) Climate Change 2014: Synthesis Report. Contribution of Working Groups I, II and III to the Fifth Assessment Report of the Intergovernmental Panel on Climate Change [Core Writing Team, R.K. Pachauri and L.A. Meyer (eds.)]. IPCC, Geneva, Switzerland, 151 pp. Jacob D, Petersen J, Eggert B, Alias A, Bøssing Christensen O et al. (2014) EURO-CORDEX: new highresolution climate change projections for European impact research. Reg Environ Change 14:563578. https://doi.org/10.1007/s10113-013-0499-2

Jacob S, Burkhard B, Van Daele TV, Staes J, Schneiders A (2015) 'The Matrix Reloaded': A review of expert knowledge use for mapping ecosystem services. Ecological Modelling 295:21-30.

https://doi.org/10.1016/i.ecolmodel.2014.08.024

Kettle NP, Dow K, Tuler S, Webler T, Whitehead J, Miller KM (2014) Integrating scientific and local knowledge to inform risk-based management approaches for climate adaptation. Climate Risk Management 4-5:17-31.https://doi.org/10.1016/i.crm.2014.07.001

Klein J.T (2020) Sustainability and Collaboration: Crossdisciplinary and Cross-Sector Horizons. Sustainability 220, 12, 1515. https://doi.org/10.3390/su12041515 
Locatelli B, Lavorel S, Sloan S, Tappeiner U, Geneletti D (2017) Characteristic trajectories of ecosystem services in mountains. Front Ecol Environ 15:150-159.

\section{https://doi.org/10.1002/fee.1470}

McDowell G, Huggel C, Frey H, Wang FM, Cramer K et al. (2019) Adaptation action and research in glaciated mountain systems: Are they enough to meet the challenge of climate change? Global Environmental Change 54:19-30.https://doi.org/10.1016/j.gloenvcha.2018.10.012 Meadow AM, Ferguson DB, Guido Z, Horangic A, Owen G et al. (2015) Moving toward the Deliberate Coproduction of Climate Science Knowledge. Weather, Climate, and Society 7:179-191. https://doi.org/10.1175/WCAS-D-14-00050.1

Morin S, Arlot MP (2019) Services climatiques: des outils pour les territoires ? Revue Science Eaux \& Territoires, Changement climatique: quelle stratégie d'adaptation pour les territoires de montagne ?, numéro 28, p. 84-89, 01/08/2019. https://doi.org/10.3917/set.028.0084 Morin S, Abegg B, Demiroglu OC, Pons M, Weber F et al. (2018) The mountain component of the Copernicus Climate Change Services - Sectoral Information Service "European Tourism": towards pan-European analysis and projections of natural and managed snow conditions, 542 - 547, International Snow Science Workshop Proceedings 2018, Innsbruck, Austria, 2018.

https://arc.lib.montana.edu/snow-science/item.php?id=2593 Nicolescu, N (1996) La Transdisciplinarité: Manifeste. Edition du Rocher, 231p.

ORCAE (2016). Le changement climatique en Rhône-Alpes. Profil climat: « Montagne - Alpes du Nord ». https://www.orcae-auvergne-rhone-

alpes.fr/fileadmin/user upload/mediatheque/ORCAE/Documents/Publications/ORECC profil terri torial montagne alpes VF juin16.pdf

Otero I, Castellnou M, Gonzalez I, Arilla E, Castell L, Castellvı J, Sanchez F, Nielsen JØ (2018) Democratizing wildfire strategies. Do you realize what it means? Insights from a participatory process in the Montseny region (Catalonia, Spain). PLOS ONE.

\section{https://doi.org/10.1371/journal.pone.0204806}

Reed M.S (2008) Stakeholder participation for environmental management: A literature review, Biological Conservation, Volume 141, Issue 10. https://doi.org/10.1016/i.biocon.2008.07.014. Reyes-García V, Fernández-Llamazares A, Guèze M, Garcés A, Mallo M et al. (2016) Local indicators of climate change: the potential contribution of local knowledge to climate research - WIREs Clim Change, 7:109-124. https://doi.org/10.1002/wcc.374

Ruckelshaus M, McKenzie E, Tallis H, Guerry A, Daily G et al. (2015) Notes from the field: Lessons learned from using ecosystem service approaches to inform real-world decisions. Ecological Economics 115:11-21. https://doi.org/10.1016/i.ecolecon.2013.07.009

Senge P (2006) The Fifth Discipline: The Art and Practice of the Learning Organization. Business \& Economics, Random House Business; 2Rev e. édition (6 avril 2006). 
Smeets E, Weterings R (1999) Environmental indicators: Typology and overview. Technical report No 25. European Environment Agency, 19p.

Spandre P, François H, Verfaillie D, Lafaysse M, Déqué M et al. (2019) Climate controls on snow reliability in French Alps ski resorts. Sci Rep 9:8043. https://doi.org/10.1038/s41598-019-44068-8 Tasser E, Leitinger G, Tappeiner U (2017) Climate change versus land-use change-What affects the mountain landscapes more? Land Use Policy 60:60-72.

\section{https://doi.org/10.1016/j.landusepol.2016.10.019}

Thonicke K, Bahn M, Lavorel S, Bardgett R.D, Erb K et al. (2020) Advancing the understanding of adaptive capacity of social-ecological systems to absorb climate extremes. Earth's Future, 8 , e2019EF001221.https://doi.org/10.1029/2019EF001221

Tschanz L (2019) La prospective, une démarche pour explorer la sensibilité du territoire au changement climatique. Sciences Eaux \& Territoires $N^{\circ}$ 28:24.

\section{https://doi.org/10.3917/set.028.0024}

Uittenbroek CJ, Mees HLP, Hegger DLT, Driessen PPJ (2019) The design of public participation: who participates, when and how? Insights in climate adaptation planning from the Netherlands. Journal of Environmental Planning and Management 62:2529-2547.

\section{https://doi.org/10.1080/09640568.2019.1569503}

Vannier C, Lasseur R, Crouzat E, Byczek C, Lafond V et al. (2019) Mapping ecosystem services bundles in a heterogeneous mountain region. Ecosystems and People 15:74-88.

\section{https://doi.org/10.1080/26395916.2019.1570971}

Verfaillie D, Déqué M, Morin S, Lafaysse M (2017) The method ADAMONT v1.0 for statistical adjustment of climate projections applicable to energy balance land surface models. Geosci Model Dev 10:4257-4283. https://doi.org/10.5194/gmd-10-4257-2017

Verfaillie D, Lafaysse M, Déqué M, Eckert N, Lejeune $Y$ et al. (2018) Multi-component ensembles of future meteorological and natural snow conditions for $1500 \mathrm{~m}$ altitude in the Chartreuse mountain range, Northern French Alps. The Cryosphere 12:1249-1271. https://doi.org/10.5194/tc-12-1249$\underline{2018}$

Vidaud-Barral L, Pinet F, Tacnet J and Jousselme A (2020) Combining UML Profiles to Design Serious Games Dedicated to Trace Information in Decision Processes. International Journal of Information System Modeling and Design (IJISMD), 11(2), 1-27.

https://doi:10.4018/IJISMD.2020040101

Vij S, Biesbroek R, Adler C, and Muccione V (2021) Climate Change Adaptation in European Mountain Systems: A Systematic Mapping of Academic Research. Mountain Research and Development. https://doi.org/10.1659/MRD-JOURNAL-D-20-00033

Webb R, Rissik D, Petheram L, Beh JL and Smith MS (2019) Co-designing adaptation decision support: meeting common and differentiated needs. Climatic Change 153:569-585. 
https://doi.org/10.1007/s10584-018-2165-7 